\title{
ORIGINAL
}

\section{COVID-19 in critical care: epidemiology of the first epidemic wave across England, Wales and Northern Ireland}

\author{
Alvin Richards-Belle ${ }^{1} \mathbb{D}$, Izabella Orzechowska ${ }^{10}$, Doug W. Gould ${ }^{1} \mathbb{D}$, Karen Thomas ${ }^{1} \mathbb{D}$, James C. Doidge ${ }^{1}$,

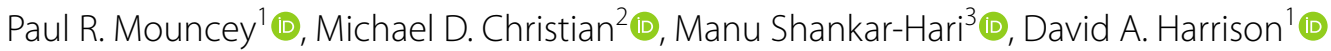 \\ and Kathryn M. Rowan ${ }^{1 *}$ (D) on behalf of the ICNARC COVID-19 Team
}

(c) Springer-Verlag GmbH Germany, part of Springer Nature 2020, corrected publication 2021

\begin{abstract}
Purpose: To describe critical care patients with COVID-19 across England, Wales and Northern Ireland and compare them with a historic cohort of patients with other viral pneumonias (non-COVID-19) and with international cohorts of COVID-19.

Methods: Extracted data on patient characteristics, acute illness severity, organ support and outcomes from the Case Mix Programme, the national clinical audit for adult critical care, for a prospective cohort of patients with COVID-19 (February to August 2020) are compared with a recent retrospective cohort of patients with other viral pneumonias (non-COVID-19) (2017-2019) and with other international cohorts of critical care patients with COVID-19, the latter identified from published reports.

Results: 10,834 patients with COVID-19 (70.1\% male, median age 60 years, 32.6\% non-white ethnicity, 39.4\% obese, $8.2 \%$ at least one serious comorbidity) were admitted across 289 critical care units. Of these, $36.9 \% \mathrm{had}$ a $\mathrm{PaO}_{2} / \mathrm{FiO}_{2}$ ratio of $\leq 13.3 \mathrm{kPa}(\leq 100 \mathrm{mmHg})$ consistent with severe ARDS and $72 \%$ received invasive ventilation. Acute hospital mortality was 42\%, higher than for 5782 critical care patients with other viral pneumonias (non-COVID-19) (24.7\%), and most COVID-19 deaths (88.7\%) occurred before 30 days. Meaningful international comparisons were limited due to lack of standardised reporting.

Conclusion: Critical care patients with COVID-19 were disproportionately non-white, from more deprived areas and more likely to be male and obese. Conventional severity scoring appeared not to adequately reflect their acute severity, with the distribution across $\mathrm{PaO}_{2} / \mathrm{FiO}_{2}$ ratio categories indicating acutely severe respiratory disease. Critical care patients with COVID-19 experience high mortality and place a great burden on critical care services.
\end{abstract}

Keywords: COVID-19, Coronavirus, Critical care, Pandemic, Outcomes

\footnotetext{
*Correspondence: kathy.rowan@icnarc.org

1 Intensive Care National Audit and Research Centre (ICNARC), Napier

House, 24 High Holborn, London WC1V 6AZ, UK

Full author information is available at the end of the article

Alvin Richards-Belle and Izabella Orzechowska are joint first authors.
}

ICNARC COVID-19 Team Group members are listed in the Acknowledgements section.

\section{实 Springer}




\section{Introduction}

Since originating in late 2019, in Wuhan China, severe acute respiratory syndrome coronavirus 2 , the virus associated with coronavirus disease 2019 (COVID-19), has rapidly spread across the world [1]. As of 16 September 2020, almost 30 million cases were reported, associated with approaching one million deaths [2], including 41,664 in the United Kingdom (UK), representing unprecedented numbers of critically ill patients and intense demand on critical care services, globally $[3,4]$.

Accurate and reliable analyses of the epidemiology of COVID-19 in critical care are essential for monitoring patient outcomes and informing planning for future service provision [5]. In the UK, prior to the epidemic, as COVID-19 was a new disease, planning for service provision was informed by recent historic data on a likely similar condition and by emerging data from international cohorts of critical care patients with COVID-19. As the epidemic emerged, the Intensive Care National Audit \& Research Centre (ICNARC), through its national clinical audit (the Case Mix Programme-CMP) was well placed to rapidly collate, analyse and report data on critical care patients with COVID-19.

Now, as the first wave of the epidemic is waning, the primary aim of this study was to describe the epidemiology of COVID-19 in critical care across the UK (England, Wales and Northern Ireland-the remit of the CMP). Our first objective was to describe the patient characteristics, acute illness severity, organ support and outcomes of critical care patients with COVID-19. Our second objective was to compare critical care patients with COVID-19 to a recent historic cohort of critical care patients with other viral pneumonias (non-COVID-19). Our third objective was to compare critical care patients with COVID-19 across reported international cohorts.

\section{Methods}

\section{Data sources}

Two cohorts of critical care patients admitted to critical care units participating in the CMP-one, prospective, of patients with confirmed COVID-19 (Objective 1) and one, recent but retrospective, of patients with other viral pneumonias (non-COVID-19) (Objective 2) and international cohorts of critical care patients with COVID-19 from published reports (Objective 3).

\section{Data}

For Objective 1, consecutive patients, from 1 February to 31 August, 2020, identified from their first admission with confirmed COVID-19 (confirmed either at or after the start of critical care) to one of 289 National Health Service (NHS) adult critical care units (standalone and

\section{Take-home message}

Critical care patients with COVID-19 were disproportionately nonwhite, from more deprived areas and more likely to be male and obese. Conventional severity scoring appeared not to adequately reflect their acute severity, with the distribution across $\mathrm{PaO}_{2} / \mathrm{FiO}_{2}$ ratio categories indicating acutely severe respiratory disease. Critical care patients with COVID-19 experience high mortality and place a great burden on critical care services.

combined intensive care/high dependency units) in England, Wales and Northern Ireland (100\% coverage) routinely submitting data to the CMP. Comprehensive testing for COVID-19 was mandated in all NHS critical care units from 2 March 2020 [6]. Critical care patients with COVID-19 were defined as either those with a positive test (according to local practice) or those with a clinical diagnosis of COVID-19 in the context of a negative test where the treating clinical team were strongly convinced that the test was a false negative and the patient was treated as a confirmed COVID-19 patient.

For Objective 2, data for a historic cohort of critical care patients, between 1 January 2017 and 31 December 2019, with other viral pneumonias (non-COVID-19) were extracted from the CMP database. Other viral pneumonias (non-COVID-19) were identified where the primary reason for admission to critical care was coded as viral pneumonia using the ICNARC Coding Method (ICM) [7]. The ICM generates a hierarchical code based on selection of body system (respiratory), anatomical site (lungs), physiological/pathological process (infection), and final condition (viral pneumonia). Viral pneumonia could be influenza or non-influenza related. Codes for pneumonia of non-viral origin (e.g. bacterial, parasitic, etc.) or where no organism was isolated were excluded.

CMP data included a unique national patient identifier; patient characteristics, type and duration of organ support and outcome. Patient characteristics included date of birth; usual residential postcode; sex; ethnicity (using NHS ethnicity codes); height; weight; duration of hospital stay prior to critical care admission; source of admission to critical care; past medical history; level of care (intensive or high dependency) at admission; and lowest and highest values for specific physiological parameters during the first $24 \mathrm{~h}$ of admission. Past medical history data covered: prior dependency (based on levels of assistance with daily activities); and serious morbidities (cardiovascular, respiratory, renal, liver, metastatic disease, haematological malignancy and immunocompromise) evident in the prior 6 months.

At acute hospital discharge, data submitted included dates and times of critical care admission and discharge (including those for readmissions during the same acute 
hospital stay); calendar days (00:00 to 23:59) of organ support in critical care (respiratory, cardiovascular, renal, neurological), as defined by the NHS Critical Care Minimum Data Set (CCMDS) [8]; date of acute hospital discharge; and status at critical care unit and acute hospital discharge. The CMP has support for the collection and use of patient-identifiable data without consent under Section 251 of the NHS Act 2006 (approval number PIAG 2-10(f)/2005). As a service evaluation, approval from a Research Ethics Committee was not required (UK Health Research Authority).

For Objective 3, a literature search for international cohorts of critical care patients with COVID-19 was conducted. Reports including more than 5 sites and more than 200 patients were included.

\section{Statistical analysis}

For Objectives 1 and 2, multiple admissions for the same patient were linked using the unique national identifier (NHS number) and combined into a single patient record. Patient characteristics presented derive from the first critical care admission.

Age was derived from dates of birth and admission to critical care and categorised in three groups $(<50,50-69$, $70+$ ). Recorded ethnicity codes were grouped into five categories (White, Asian, Black, Mixed/other and not stated). Patients' residential postcodes were linked to the index of multiple deprivation (IMD), assigned at the level of Lower Layer Super Output Area according to the 2019 Indices of Multiple Deprivation for England and Wales and the 2017 Multiple Deprivation Measure for Northern Ireland, and categorised at quintiles of the national distribution. Body mass index (BMI), calculated as weight $(\mathrm{kg})$ divided by height $(\mathrm{m})$ squared (where actual values not available, estimated values were used) was categorised into standard NHS BMI categories.

Prior dependency in relation to daily activities was considered in three categories: independent (no assistance); some dependency (minor or major assistance); and dependent (total assistance).

Prior hospital stay was calculated from dates of admission to acute hospital and to critical care. Source of admission to critical care was categorised into four groups (emergency department, ward, other hospital location or not in hospital).

The $\mathrm{PaO}_{2} / \mathrm{FiO}_{2}$ ratio ( $P / F$ ratio), derived from the arterial blood gas with the lowest $\mathrm{PaO}_{2}$ during the first $24 \mathrm{~h}$, was categorised to reflect mild [ $>200 \mathrm{mmHg}$ $(>26.7 \mathrm{kPa})]$, moderate $[>100$ and $\leq 200 \mathrm{mmHg}(>13.3$ and $\leq 26.7 \mathrm{kPa})]$ and severe $[\leq 100 \mathrm{mmHg}(\leq 13.3 \mathrm{kPa})]$ acute respiratory distress syndrome (ARDS) [9].
Lowest and highest values for physiological parameters during the first $24 \mathrm{~h}$ of admission were used to calculated the Acute Physiology and Chronic Health Evaluation (APACHE) II [10] acute physiology score and the APACHE II score. The former (0-60) is based on weighting any deviation from the normal range for twelve physiological parameters [temperature, heart rate, respiratory rate, arterial $\mathrm{pH}$, serum sodium, serum creatinine, white blood cell count, Glasgow Coma Score, mean arterial pressure, A-aDO2 (if $\mathrm{FiO}_{2} \geq 0.5$ ) or $\mathrm{PaO}_{2}$ (if $\mathrm{FiO}_{2}<0.5$ ), serum potassium and haematocrit (estimated from haemoglobin)]. The latter (0-71) adds additional weights for age and for serious comorbidities to the APACHE II acute physiology score.

Total duration of stay in critical care was calculated in calendar days from the dates of admission to and discharge from critical care, excluding any periods in the acute hospital stay outside critical care. In survival analyses, patients discharged from acute hospital prior to 90 days were assumed to be alive at 90 days.

Analyses used all available data and were conducted using Stata/SE version 16.1 (StataCorp LP). Levels of missing data are presented in eFigure 1. Descriptive statistics were used to summarise data, with results reported as means with standard deviations (SD), medians with interquartile ranges (IQRs), or counts and percentages, as appropriate. Results for age, sex, ethnicity and BMI were contextualised using general population data from the 2011 National UK censuses [11] and 2018 Health Survey for England [12]. For Objective 3, reported data were extracted from published reports and tabulated using a standardized data extraction form.

\section{Results}

Patient characteristics, acute illness severity, organ support and outcomes of critical care patients with COVID-19 (Objective 1)

Of 289 critical care units, 258 had at least one admission with COVID-19. In total, between 1 February and 31 August 2020, 10,834 patients with COVID-19 were admitted: $41 \%$ presenting as high dependency and $59 \%$ as intensive care patients. Patient characteristics, acute illness severity, organ support and outcomes are presented in Table 1. Patients had a median (IQR) age of 60 (51-68); just over $21 \%$ were aged under 50 , with a similar proportion aged 70 or more. Over two-thirds $(70.1 \%)$ were male and one-third (32.6\%) were of non-white ethnicity. The median (IQR) BMI for the cohort was $28.3(24.8-33) \mathrm{kg} /$ $\mathrm{m}^{2}$; almost $40 \%$ were considered obese (BMI $\left.\geq 30\right)$. Prior to admission, most $(89.4 \%)$ were reported as being able to live independently and $8.2 \%$ had at least one documented serious comorbidity. 
Table 1 Characteristics, acute illness severity, outcomes and organ support of critical care patients with COVID-19 compared with critical care patients with other viral pneumonias (non-COVID-19)

\begin{tabular}{|c|c|c|}
\hline & $\begin{array}{l}\text { Patients with COVID-19 } \\
(N=10,834)\end{array}$ & $\begin{array}{l}\text { Patients with other viral } \\
\text { pneumonias (non-COVID-19) } \\
(N=5782)\end{array}$ \\
\hline \multicolumn{3}{|l|}{ Patient characteristics } \\
\hline Age (years), median (IQR) & $60(51-68)$ & $61(48-71)$ \\
\hline \multicolumn{3}{|l|}{ Age categories (years), $n$ (\%) } \\
\hline$<50$ & $2331(21.5 \%)$ & $1594(28.4 \%)$ \\
\hline $50-69$ & $6203(57.3 \%)$ & $2361(42.1 \%)$ \\
\hline $70+$ & $2290(21.2 \%)$ & $1654(29.5 \%)$ \\
\hline \multicolumn{3}{|l|}{ Sex, $n(\%)$} \\
\hline Female & 3237 (29.9\%) & $2641(45.7 \%)$ \\
\hline Male & 7590 (70.1\%) & $3141(54.3 \%)$ \\
\hline \multicolumn{3}{|l|}{ Ethnicity, $n(\%)$} \\
\hline White & $6885(63.5 \%)$ & $4951(85.6 \%)$ \\
\hline Asian & $1657(15.3 \%)$ & $325(5.6 \%)$ \\
\hline Black & $995(9.2 \%)$ & $155(2.7 \%)$ \\
\hline Mixed & $190(1.8 \%)$ & $52(0.9 \%)$ \\
\hline Other & $691(6.4 \%)$ & $117(2 \%)$ \\
\hline Not stated & $416(3.8 \%)$ & $182(3.1 \%)$ \\
\hline \multicolumn{3}{|l|}{ Quintile of index of multiple deprivation ${ }^{\mathrm{a}}$} \\
\hline 1-least deprived & $1421(14.2 \%)$ & $873(15.3 \%)$ \\
\hline 2 & $1599(16 \%)$ & $999(17.5 \%)$ \\
\hline 3 & 1944 (19.5\%) & $1115(19.5 \%)$ \\
\hline 4 & $2383(23.9 \%)$ & $1232(21.6 \%)$ \\
\hline 5-most deprived & $2641(26.4 \%)$ & $1489(26.1 \%)$ \\
\hline BMI $\left(\mathrm{kg} / \mathrm{m}^{2}\right)$, median (IQR) & $28.3(24.8-33)$ & $26.6(23.1-31.2)$ \\
\hline \multicolumn{3}{|l|}{ BMI categories $\left(\mathrm{kg} / \mathrm{m}^{2}\right), n(\%)$} \\
\hline 18.5 to $<25$ & $2704(26.3 \%)$ & $2243(39.6 \%)$ \\
\hline 25 to $<30$ & $3525(34.3 \%)$ & $1691(29.9 \%)$ \\
\hline 30 to $<40$ & $3231(31.4 \%)$ & $1330(23.5 \%)$ \\
\hline $40+$ & $822(8 \%)$ & $394(7 \%)$ \\
\hline \multicolumn{3}{|l|}{ Prior dependency, $n$ (\%) } \\
\hline Able to live without assistance in daily activities & $9580(89.4 \%)$ & $4244(73.6 \%)$ \\
\hline Some assistance with daily activities & 1094 (10.2\%) & $1392(24.1 \%)$ \\
\hline Total assistance with all daily activities & $40(0.4 \%)$ & $134(2.3 \%)$ \\
\hline \multicolumn{3}{|l|}{ Serious comorbidities ${ }^{\mathrm{b}}, n(\%)$} \\
\hline Cardiovascular & $68(0.6 \%)$ & $78(1.4 \%)$ \\
\hline Respiratory & $128(1.2 \%)$ & $295(5.1 \%)$ \\
\hline Renal & $183(1.7 \%)$ & $120(2.1 \%)$ \\
\hline Liver & $51(0.5 \%)$ & $54(0.9 \%)$ \\
\hline Metastatic disease & $59(0.6 \%)$ & $68(1.2 \%)$ \\
\hline Haematological malignancy & $208(1.9 \%)$ & $268(4.6 \%)$ \\
\hline Immunocompromise & $382(3.6 \%)$ & $503(8.7 \%)$ \\
\hline Any & $883(8.2 \%)$ & $1059(18.4 \%)$ \\
\hline Prior hospital stay (days), median (IQR) & $1(0-3)$ & $1(0-2)$ \\
\hline \multicolumn{3}{|l|}{ Source of admission, $n$ (\%) } \\
\hline Not in hospital & $13(0.1 \%)$ & $12(0.2 \%)$ \\
\hline Emergency department & $3636(33.6 \%)$ & 2264 (39.2\%) \\
\hline Ward & $6571(60.7 \%)$ & $2859(49.4 \%)$ \\
\hline Other hospital location ${ }^{c}$ & $614(5.7 \%)$ & $647(11.2 \%)$ \\
\hline
\end{tabular}


Table 1 (continued)

\begin{tabular}{|c|c|c|}
\hline & $\begin{array}{l}\text { Patients with COVID-19 } \\
(N=10,834)\end{array}$ & $\begin{array}{l}\text { Patients with other viral } \\
\text { pneumonias (non-COVID-19) } \\
(N=5782)\end{array}$ \\
\hline \multicolumn{3}{|l|}{ Acute illness severity ${ }^{d}$} \\
\hline P/F ratio $(\mathrm{kPa}),{ }^{\mathrm{e}}$ median $(\mathrm{IQR})$ & $15.8(11.3-22)$ & $18(11.6-26.4)$ \\
\hline \multicolumn{3}{|l|}{$P / F$ ratio categories $(\mathrm{kPa})^{\mathrm{e}}$} \\
\hline$\leq 13.3 \mathrm{kPa}(\leq 100 \mathrm{mmHg})$ & $3758(36.9 \%)$ & $1819(33.2 \%)$ \\
\hline $13.3-26.7 \mathrm{kPa}(100-200 \mathrm{mmHg})$ & $4871(47.8 \%)$ & $2318(42.4 \%)$ \\
\hline$>26.7 \mathrm{kPa}(>200 \mathrm{mmHg})$ & $1551(15.2 \%)$ & $1328(24.3 \%)$ \\
\hline APACHE II acute physiology score, median (IQR) & $11(8-14)$ & $13(9-16)$ \\
\hline APACHE II score, ${ }^{9}$ median (IQR) & $15(11-18)$ & $17(13-21)$ \\
\hline \multicolumn{3}{|l|}{ Organ support in critical care ${ }^{\mathrm{h}, \mathrm{i}}$} \\
\hline \multicolumn{3}{|l|}{ Advanced respiratory support } \\
\hline Receipt, $n$ (\%) & $7702(72 \%)$ & $2721(48.4 \%)$ \\
\hline Duration (calendar days), median (IQR) & $13(7-23)$ & $9(4-17)$ \\
\hline \multicolumn{3}{|l|}{ Basic respiratory support (only) } \\
\hline Receipt, $n$ (\%) & $2736(25.6 \%)$ & 2609 (46.4\%) \\
\hline Duration (calendar days), median (IQR) & $4(3-7)$ & $3(2-5)$ \\
\hline \multicolumn{3}{|l|}{ Advanced cardiovascular support } \\
\hline Receipt, $n(\%)$ & $3255(30.4 \%)$ & $1261(22.4 \%)$ \\
\hline Duration (calendar days), median (IQR) & $3(2-6)$ & $3(2-5)$ \\
\hline \multicolumn{3}{|l|}{ Basic cardiovascular support (only) } \\
\hline Receipt, $n$ (\%) & $6969(65.1 \%)$ & $4134(73.5 \%)$ \\
\hline Duration (calendar days), median (IQR) & $9(5-18)$ & $5(3-10)$ \\
\hline \multicolumn{3}{|l|}{ Renal support } \\
\hline Receipt, $n$ (\%) & $2850(26.7 \%)$ & $957(17 \%)$ \\
\hline Duration (calendar days), median (IQR) & $8(3-15)$ & $6(3-12)$ \\
\hline \multicolumn{3}{|l|}{ Neurological support } \\
\hline Receipt, $n$ (\%) & $973(9.1 \%)$ & $320(5.7 \%)$ \\
\hline Duration (calendar days), median (IQR) & $4(2-9)$ & $2.5(1-5)$ \\
\hline \multicolumn{3}{|l|}{ Outcomes } \\
\hline \multicolumn{3}{|l|}{ Critical care } \\
\hline Survived, $n(\%)$ & $6464(59.7 \%)$ & $4423(76.5 \%)$ \\
\hline Died, $n(\%)$ & $4240(39.1 \%)$ & $1203(20.8 \%)$ \\
\hline Last known to be still in unit, $n(\%)$ & $130(1.2 \%)$ & $156(2.7 \%)$ \\
\hline \multicolumn{3}{|l|}{ Acute hospital } \\
\hline Survived, $n(\%)$ & $5868(54.2 \%)$ & $4156(71.9 \%)$ \\
\hline Died, $n(\%)$ & $4554(42 \%)$ & $1427(24.7 \%)$ \\
\hline Last known to be still in acute hospital, $n(\%)$ & $412(3.8 \%)$ & $199(3.4 \%)$ \\
\hline \multicolumn{3}{|l|}{ Duration of stay (calendar days) } \\
\hline Critical care, median (IQR) & $10(5-22)$ & $6(3-13)$ \\
\hline Survived, median (IQR) & $12(5-27)$ & $6(3-13)$ \\
\hline Died, median (IQR) & $9(5-16)$ & $6(2-13)$ \\
\hline Acute hospital, median (IQR) & $17(9-32)$ & $14(8-28)$ \\
\hline Survived, median (IQR) & $24(12-43)$ & $15(9-30)$ \\
\hline Died, median (IQR) & $12(7-19)$ & $9(4-18)$ \\
\hline
\end{tabular}




\section{Table 1 (continued)}

$B M I$ body mass index, CPR cardiopulmonary resuscitation, $P / F$ ratio $\mathrm{PaO}_{2} / \mathrm{FiO}_{2}$ ratio, ICNARC Intensive Care National Audit \& Research Centre, APACHE II Acute Physiology and Chronic Health Evaluation, Second Version

a Higher values indicate greater deprivation

b Serious comorbidities are defined as cardiovascular: symptoms of fatigue, claudication, dyspnoea or angina at rest; respiratory: shortness of breath with light activity or home ventilation; renal: receipt of renal replacement therapy for end-stage renal disease; liver: biopsy-proven cirrhosis, portal hypertension or hepatic encephalopathy; metastatic disease: distant metastases; haematological malignancy: acute or chronic leukaemia, multiple myeloma or lymphoma; and immunocompromise: receipt of chemotherapy, radiotherapy or daily high-dose steroid treatment in previous 6 months, HIV/AIDS or a congenital immune deficiency

c Other hospital location includes obstetrics areas, intermediate care areas, theatres, recovery, imaging departments, specialist treatment areas and clinics

d Within $24 \mathrm{~h}$ of admission to the critical care unit

e $P / F$ ratio derived from the arterial blood gas with the lowest $\mathrm{PaO}_{2}$ during the first $24 \mathrm{~h}$

f APACHE II acute physiology score (range 0-60) was calculated using physiological parameters recorded during the first $24 \mathrm{~h}$ in the critical care unit

9 APACHE II score (range 0-71; higher scores indicate greater severity) was calculated using the APACHE II acute physiology score plus weightings for age and serious comorbidities

h Based on patients discharged alive from, or died in, critical care. Organ supports are defined according to Critical Care Minimum Data Set [8] as Advanced respiratory support: invasive ventilation, BPAP via trans-laryngeal tube or tracheostomy, CPAP via trans-laryngeal tube, extracorporeal respiratory support; Basic respiratory support: $>50 \%$ oxygen by face mask, close observation due to potential for acute deterioration, physiotherapy/suction to clear secretions at least twohourly, recently extubated after a period of mechanical ventilation, mask/hood CPAP/BPAP, non-invasive ventilation, CPAP via a tracheostomy, intubated to protect airway; Advanced cardiovascular support: multiple IV/rhythm controlling drugs (at least one vasoactive), continuous observation of cardiac output, intra-aortic balloon pump, temporary cardiac pacemaker; Basic cardiovascular support: central venous catheter, arterial line, single IV vasoactive/rhythm controlling drug; Renal support: acute renal replacement therapy, renal replacement therapy for chronic renal failure where other organ support is received; Liver support: management of coagulopathy and/or portal hypertension for acute on chronic hepatocellular failure or primary acute hepatocellular failure; Neurological support: central nervous system depression sufficient to prejudice airway, invasive neurological monitoring, continuous IV medication to control seizures, therapeutic hypothermia

' Duration of organ support is recorded as the number of calendar days (00:00-23:59) on which support was received at any time (in those receiving the organ support)

Males aged 50-79 years appeared over-represented, when compared with the age/sex distribution for the general population (Fig. 1A), while those of white ethnicity appeared under-represented, when matched on residential location for the general population (Fig. 1B). Critical care patients with COVID-19 were more likely to derive from deprived areas and more likely to be severely obese $(\mathrm{BMI} \geq 40)$ compared with the general population (Fig. 1C, D).

Over one-third of patients (36.9\%) had a $P / F$ ratio, derived from the arterial blood gas with the lowest $\mathrm{PaO}_{2}$ during the first $24 \mathrm{~h}$, of $\leq 13.3 \mathrm{kPa}(\leq 100 \mathrm{mmHg})$ consistent with severe ARDS. During the critical care unit stay, advanced respiratory support (invasive ventilation) was received by $72 \%$ of patients for a median (IQR) duration of 13 (7-23) calendar days. Advanced cardiovascular and renal support were received by $30.4 \%$ and $26.7 \%$ of patients for a median (IQR) of $3(2-6)$ and $8(3-15)$ days, respectively.

By critical care unit discharge, 4240 (39.1\%) died and 6464 (59.7\%) survived (with $1.2 \%$ still in critical care at database lock). By acute hospital discharge, 4554 (42\%) died and 5868 (54.2\%) survived (with 3.8\% still in acute hospital at database lock). Critical care survivors stayed longer in the unit than non-survivors (median duration 12 versus 9 days). Outcomes, stratified by age/sex, $P / F$ ratio categories, APACHE II acute physiology score and type and combinations of organ support received are presented in Fig. 2. Mortality increased with increasing age and severity of illness (either decreasing $P / F$ ratio category or increasing acute physiology score). Most deaths (88.7\%) and critical care unit discharges $(79.6 \%)$ occurred before day 30 and most acute hospital discharges (90.2\%) occurred before day 60 (Fig. 3).

Patient characteristics, acute illness severity, organ support and outcomes of critical care patients with COVID19 , stratified by $P / F$ ratio category and by receipt (or not) of advanced respiratory support (invasive ventilation), are presented in eTables 1 and 2.

\section{Comparison of critical care patients with COVID-19 to critical care patients with other viral pneumonias (non-COVID-19) (Objective 2)}

In total, between 1 January 2017 and 31 December 2019, 5782 patients with other viral pneumonias (nonCOVID-19) were admitted; $56.5 \%$ presenting as high dependency and $43.5 \%$ as intensive care patients. Patient characteristics, acute illness severity, organ support and outcomes are also presented in Table 1. Compared with critical care patients with COVID-19, median age was similar but a smaller proportion were male $(54.3 \%$ versus $70.1 \%)$ and of non-white ethnicity $(11.2 \%$ versus $32.6 \%)$. Critical care patients with other viral pneumonias (non-COVID-19) were more likely to have needed assistance with daily activities or to have severe conditions prior to hospitalisation than those with COVID-19. While the generic score (APACHE II) indicated slightly higher acute severity of illness for other viral pneumonias 


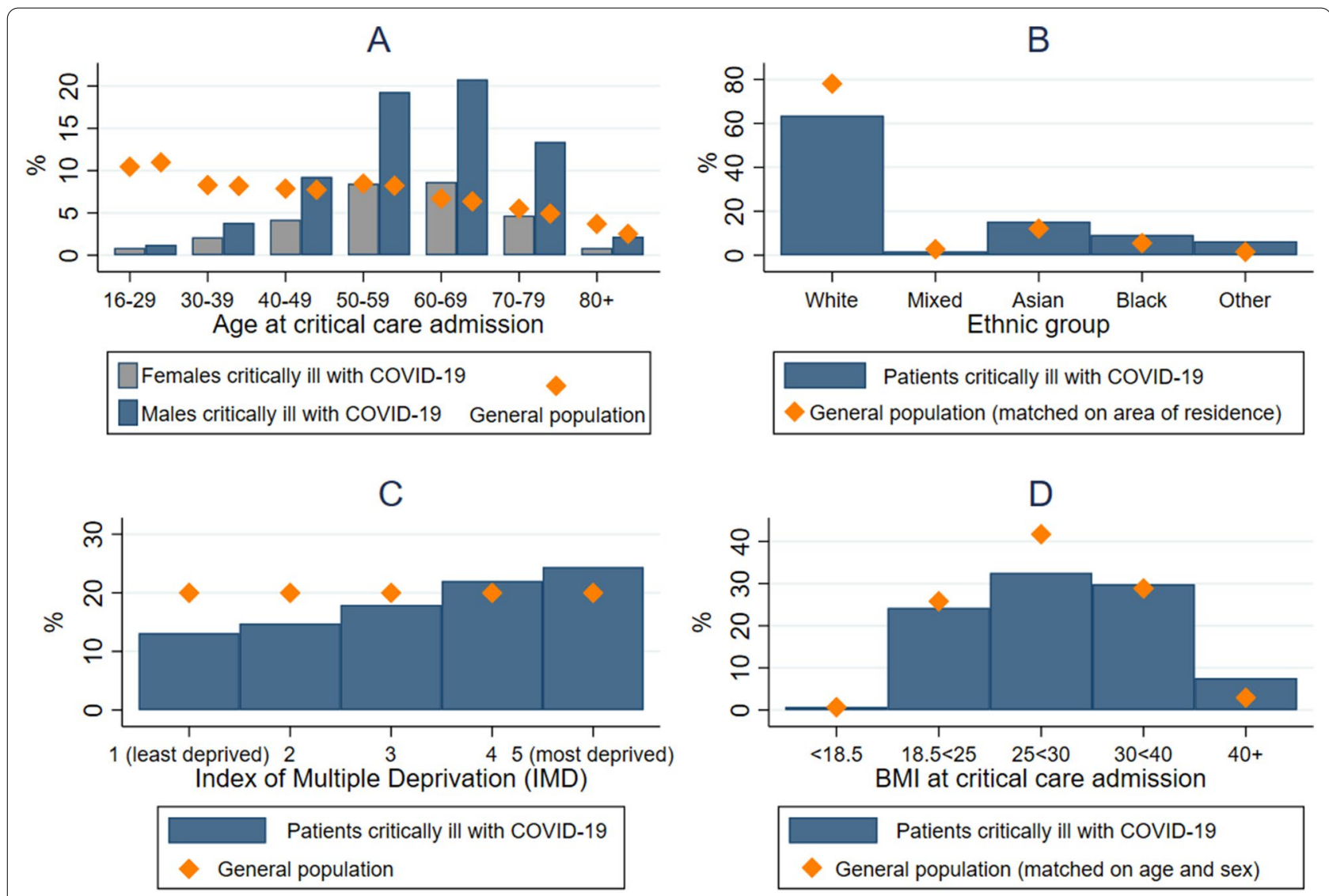

Fig. 1 Critical care patients with COVID-19 compared to the UK general population for age/sex, ethnicity, level of deprivation and body mass index

(non-COVID-19), lower $P / F$ ratios derived from the arterial blood gas with the lowest $\mathrm{PaO}_{2}$ during the first $24 \mathrm{~h}$, indicated greater severity of illness for critical care patients with COVID-19.

In-hospital mortality, whether in the critical care unit or in acute hospital, was lower for critical care patients with other viral pneumonias (non-COVID-19) compared with COVID-19, both overall and when stratified by age/sex, $P / F$ ratio category, APACHE II acute physiology score and type and combinations of organ support received (Fig. 4). Duration of stay in critical care and in acute hospital was shorter for other viral pneumonias (non-COVID-19). A greater proportion of critical care patients with COVID-19 received organ support over a greater number of calendar days, in combinations similar to critical care patients with other viral pneumonias (eFigure 2).
Comparison of critical care patients with COVID-19 across international cohorts (Objective 3 )

With regard to international comparisons, 9 studies fulfilled the a priori inclusion criteria (5 sites, 200 patients) applied to indicate some degree of representativeness [13-21]. Meaningful comparisons were limited due to lack of standardised reporting (Supplement page 2 and eTable 3).

\section{Discussion}

In this manuscript, we set out to describe the epidemiology of COVID-19 in critical care. In our large, representative cohort $(10,834$ critical care patients with COVID-19 admitted across 289 critical care units) from England, Wales and Northern Ireland, critical care patients with COVID-19 were disproportionately from non-white ethnic groups, from more deprived areas 


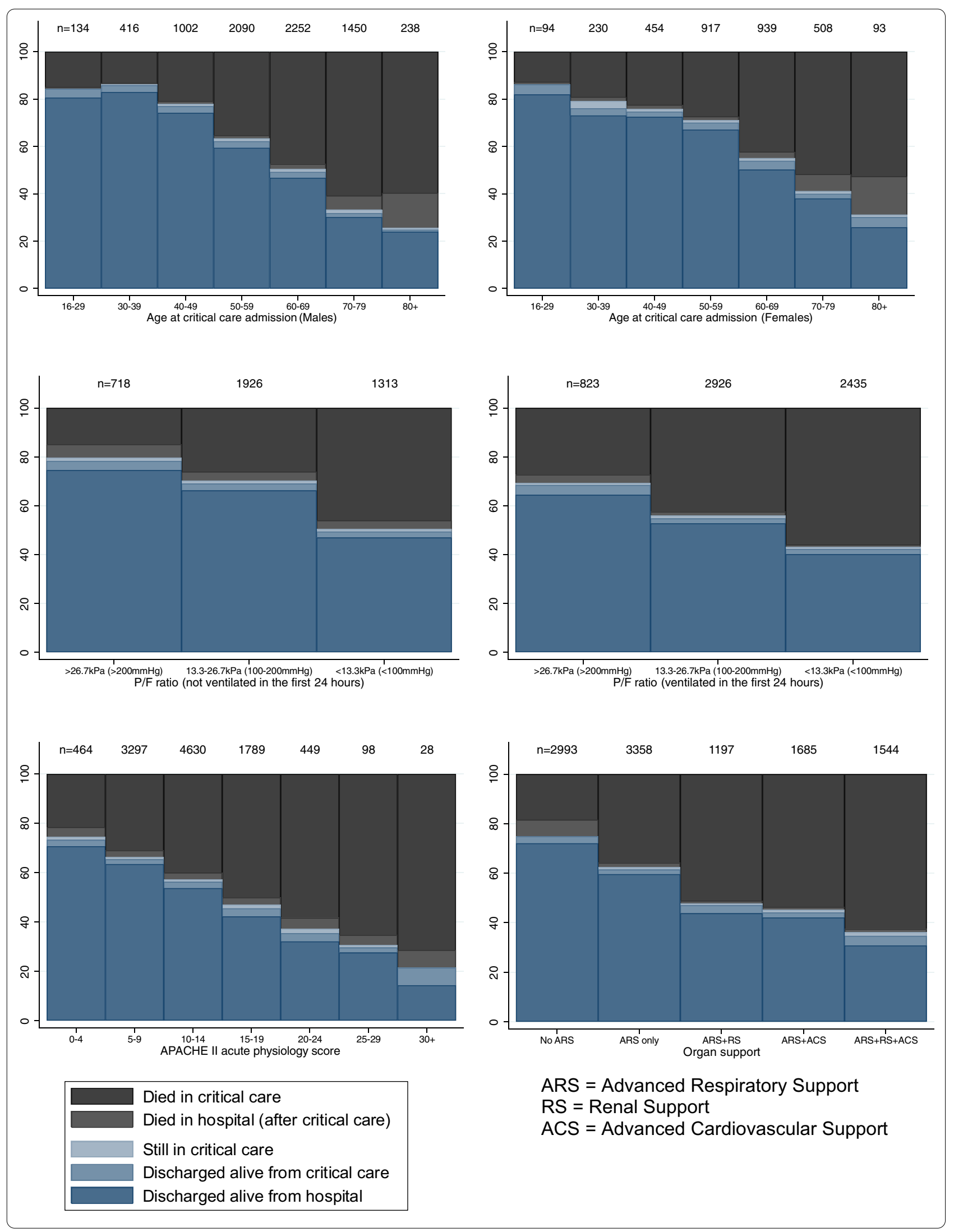




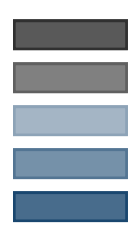

Died in critical care

Died in hospital (after critical care)

Still in critical care

Discharged alive from critical care

Discharged alive from hospital

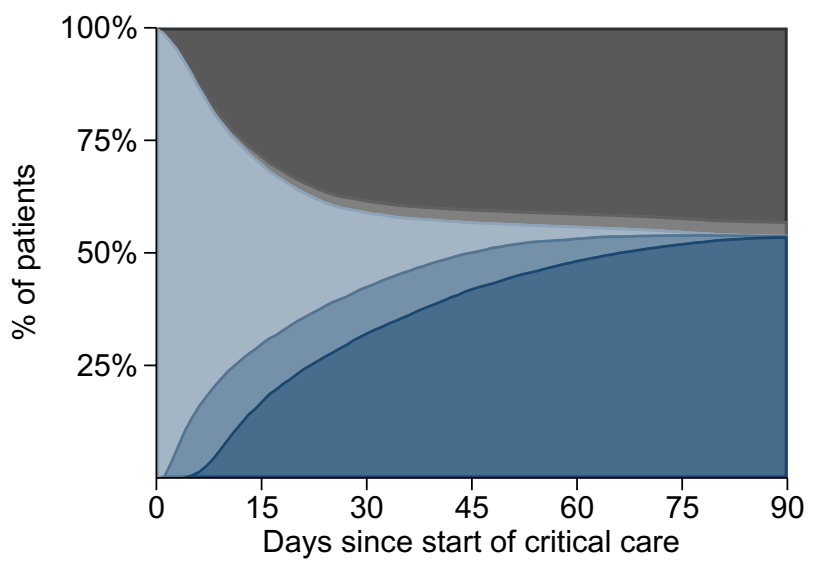

10410

0.0

0.0

100.0

0.0

0.0
10118

38.2

2.6

16.5

10.3

32.4
9868

41.1

2.9

2.6

5.0

48.4
9456

43.0

3.0

0.1

0.2

53.7

Fig. 3 Survival to acute hospital discharge for critical care patients with COVID-19. aPatients are included in this survival analysis at day 0 if they were admitted at least two weeks prior to data extraction and censored on subsequent days after reaching either their last known follow-up date, or at two weeks prior to data extraction (whichever was earliest)

and were more likely to be male and obese, relative to both the general population and to a historic cohort of critical care patients with other viral pneumonias (nonCOVID-19). Additionally, relative to critical care patients with other viral pneumonias (non-COVID-19), patients with COVID-19 reported lower prior levels of dependency and of serious comorbidities.

Conventional severity scoring (APACHE II acute physiology score) appeared not to adequately reflect the acute severity of critical care patients with COVID-19. The distribution of critical care patients with COVID19 across the more severe $P / F$ ratio categories appeared to indicate a high degree of acute severity of respiratory disease and much higher than for critical care patients with other viral pneumonias (non-COVID-19), not captured by the APACHE II acute physiology score. Acute severity was also reflected in the high mortality for critical care patients with COVID-19, much higher than for critical care patients with other viral pneumonias (nonCOVID-19) - both overall and when stratified by age/sex, $P / F$ ratio category, APACHE II acute physiology score and by type and combinations of organ support received. Overall, critical care patients with COVID-19 placed a greater burden on critical care services when compared with critical care patients with other viral pneumonias (non-COVID-19), with higher proportions receiving organ support and for longer durations.
Clearly, any direct comparisons with critical care patients with other viral pneumonias (non-COVID-19) are challenging as the historic (2017-2019) cohort derived from a non-pandemic period. It is possible that when considering the cohort of critical care patients with COVID-19 admitted during the UK epidemic wave, perceived and/or actual health care system strain and availability of beds may have led to changing triage criteria for critical care admission. This said, at the peak of the epidemic, critical care bed capacity in England was expanded from a pre-pandemic total of 4122 critical care beds ( 7.4 beds per 100,000 population) to 7560 beds equipped for invasive ventilation and 3405 beds equipped for non-invasive ventilation (19.6 beds per 100,000 population) and reported occupancy of these expanded beds never exceeded $60 \%$, nationally.

Comparison of summary statistics across reported international studies was challenging. Where comparisons were possible, available patient characteristics appeared similar but there was variation in rates of invasive ventilation and mortality. Our figures, however, are in line with a recent meta-analysis [22]. Even after considering the inherent difficulties of international comparisons, per se (e.g. system-level differences, beds per capita, staff to patient ratios, etc.) [23-25], there remains a need for greater standardisation in reporting of patient characteristics, acute illness severity, organ support and 

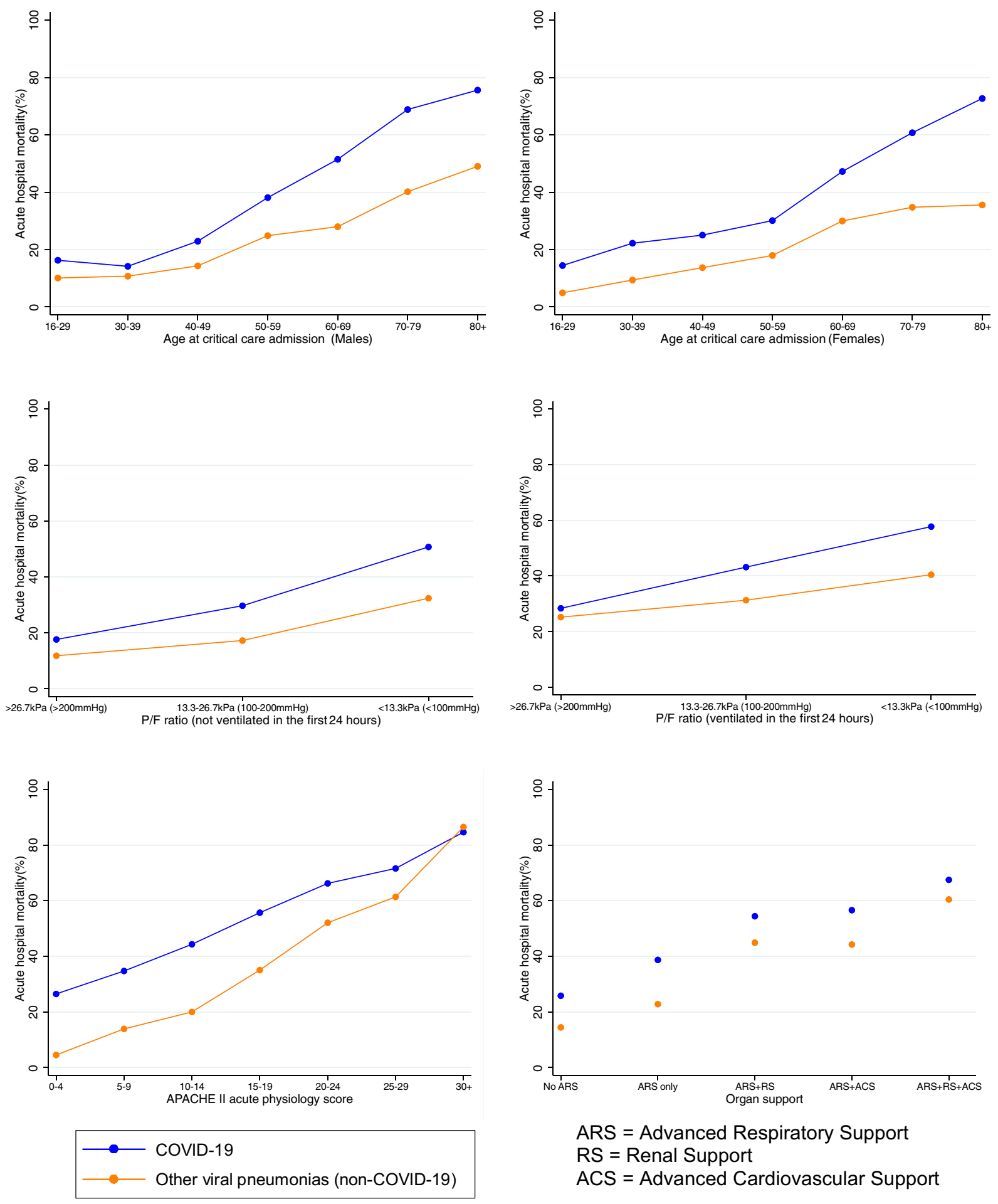

ARS = Advanced Respiratory Support

RS = Renal Support

ACS $=$ Advanced Cardiovascular Support

Fig. 4 Acute hospital mortality for critical care patients with COVID-19 compared with other viral pneumonias (non-COVID-19) by age/sex, P/F ratio category (ventilated or not in the first 24 h), APACHE II acute physiology score and type and combinations of organ support received 
outcomes for critical care cohorts, particularly in the context of a global pandemic.

This study has strengths. A major one is the $100 \%$ coverage of critical care units across three nations of the UK (Scotland reports separately) across the whole epidemic wave. We built on the lessons learned from the H1N1 pandemic where our response was too slow [26, 27]. We expedited data collection, leveraging the existing highquality clinical database of the CMP, for which data are prospectively defined and collected nationally by trained data collectors to precise rules and definitions, to which they were already familiar prior to the epidemic. The CMP database readily enabled comparison to recent historic data for patients with a relevant comparative condition [e.g. other viral pneumonias (non-COVID-19)]. We had a high level of completeness of outcome data (with only $3.8 \%$ still in acute hospital at database lock), comparing favourably with other reports [28-30] and we did not restrict our analyses to select groups.

This study has limitations. While comprehensive formal testing for COVID-19 was introduced in critical care units on 2 March 2020, it should be noted that, in an attempt to address the potential for false negatives, those patients with a clinical diagnosis of COVID-19 in the context of a negative test (less than 1\%), where the treating clinical team were convinced that the test was a false negative, were included. Our historic cohort of other viral pneumonias (non-COVID-19) were those coded with a primary reason for admission to critical care for viral pneumonia and, as such, should be regarded solely as a presumptive diagnosis of viral pneumonia. While there were strengths in adhering to the well-known dataset of the CMP, this translated into not having certain key variables that emerged as being important as knowledge around COVID-19 developed (including more specific detail on use of treatments, such as specific types of respiratory support and pharmacologic agents received as others have reported [31, 32]). Additional data were not requested to minimize the demands on staff during the pandemic. We chose to publicly report the emerging data, weekly [33], to inform our health care providers, policy-makers and the public, and waiting to the end of the epidemic wave to describe the full cohort in its entirety.

In conclusion, our cohort of 10,834 critical care patients with COVID-19 were disproportionately from non-white ethnic groups, from more deprived areas and were more likely to be male and obese. Conventional severity scoring appeared not to adequately reflect their acute severity, with the distribution across $P / F$ ratio categories appearing to indicate a high degree of acute severity of respiratory disease. Critical care patients with COVID-19 experience high mortality and place a great burden on critical care services. The observed differences when comparing critical care patients with COVID-19 to those with other viral pneumonias (non-COVID-19) demonstrated the difficulty of selecting a likely similar condition when service planning for an impending pandemic of a new disease. Thus, any service planning for a second wave should use accurate and reliable populationlevel data on patients with COVID-19. To support this, there is a need for greater standardisation in reporting of critical care cohorts internationally.

\section{Electronic supplementary material}

The online version of this article (https://doi.org/10.1007/s00134-020-06267-0) contains supplementary material, which is available to authorized users.

\section{Author details}

${ }^{1}$ Intensive Care National Audit and Research Centre (ICNARC), Napier House, 24 High Holborn, London WC1V 6AZ, UK. ${ }^{2}$ The Royal London Hospital, London's Air Ambulance, Barts Health NHS Trust, Whitechapel Road, London E1 1BB, UK. ${ }^{3}$ Intensive Care Unit, St Thomas' Hospital, Guy's and St Thomas' NHS Foundation Trust, Westminster Bridge Road, London SE1 7EH, UK.

\section{Acknowledgements}

We thank and respect all those working in critical care units across England, Wales and Northern Ireland and contributing to the care of patients and, particularly, those responsible for submitting data rapidly and regularly during the emerging COVID-19 epidemic. Additional ICNARC COVID-19 Team members: Yemi Banjo, Kasia Borowczak, Tom Cousins, Peter Cummins, Keji Dalemo, Robert Darnell, Hanna Demissie, Laura Drikite, Andrew Fleming, Ditte Frederiksen, Sarah Furnell, Abdo Hussein, Abby Koelewyn, Tim Matthews, Sam Peters, Tyrone Samuels, and Michelle Saull.

\section{Author contributions}

KR, MC, JD, DG, DH, PM, IO, ARB, MS-H, and KT conceived and designed the study. KR, DG, and ARB contributed to the acquisition of data. IO, KT, JD, and $\mathrm{DH}$ conducted the analysis of data. All authors contributed to the interpretation of data. KR, ARB, IO, DG, and PM drafted the work. All authors approved the final version to be published and agree to be accountable for all aspects of the work in ensuring that questions related to the accuracy or integrity of any part of the work are appropriately investigated and resolved.

\section{Funding}

ICNARC funded study. Dr. Shankar-Hari is supported by the National Institute for Health Research Clinician Scientist Award (CS-2016-16-011). The views expressed in this publication are those of the author(s) and not necessarily those of the NHS, National Institute for Health Research or the Department of Health and Social Care.

\section{Compliance with ethical standards}

\section{Conflicts of interest}

On behalf of all authors, the corresponding author states that there is no conflict of interest.

\section{Ethics approval}

Support for the collection and use of patient-identifiable data without consent in the Case Mix Programme has been obtained under Section 251 of the NHS Act 2006 (approval number PIAG 2-10(f)/2005).

\section{Consent to participate}

Not applicable.

Consent for publication

Not applicable. 


\section{Availability of data and material}

Requests for accessing data from the Case Mix Programme are subject to approval by an independent Data Access Advisory Group (see https://www. icnarc.org/Our-Audit/Audits/Cmp/Reports/Access-Our-Data for more details). Requests should be submitted to the corresponding author in the first instance.

\section{Code availability}

Requests should be submitted to the corresponding author in the first instance.

\section{Publisher's Note}

Springer Nature remains neutral with regard to jurisdictional claims in published maps and institutional affiliations.

Received: 20 August 2020 Accepted: 26 September 2020 Published online: 09 October 2020

\section{References}

1. World Health Organization (2020) Coronavirus disease 2019 (COVID-19) Situation Report-51. World Health Organization

2. Worldometer (2020) COVID-19 Coronavirus Pandemic. https://www. worldometers.info/coronavirus/. Accessed 16 Sept 2020

3. Arabi YM, Murthy S, Webb S (2020) COVID-19: a novel coronavirus and a novel challenge for critical care. Intensive Care Med 46(5):833-836. https://doi.org/10.1007/s00134-020-05955-1

4. Aziz S, Arabi YM, Alhazzani W, Evans L, Citerio G, Fischkoff K, Salluh J, Meyfroidt G, Alshamsi F, Oczkowski S, Azoulay E, Price A, Burry L, Dzierba A, Benintende A, Morgan J, Grasselli G, Rhodes A, Møller MH, Chu L, Schwedhelm S, Lowe JJ, Bin D, Christian MD (2020) Managing ICU surge during the COVID-19 crisis: rapid guidelines. Intensive Care Med 46(7):1303-1325. https://doi.org/10.1007/s00134-020-06092-5

5. Kain T, Fowler R (2019) Preparing intensive care for the next pandemic influenza. Crit Care 23(1):337. https://doi.org/10.1186/s13054-019-2616-1

6. Public Health England (2020) Sources of COVID-19 surveillance systems. https://www.gov.uk/government/publications/national-covid-19-surve illance-reports/sources-of-covid-19-systems. Accessed 15 Sept 2020

7. Young JD, Goldfrad C, Rowan K (2001) Development and testing of a hierarchical method to code the reason for admission to intensive care units: the ICNARC coding method. Intensive Care National Audit \& Research Centre. Br J Anaesth 87(4):543-548. https://doi.org/10.1093/bja/87.4.543

8. NHS Information Standards Board (2012) Critical care minimum data set. NHS Digital, Leeds

9. Ranieri VM, Rubenfeld GD, Thompson BT, Ferguson ND, Caldwell E, Fan E, Camporota L, Slutsky AS (2012) Acute respiratory distress syndrome: the Berlin definition. JAMA 307(23):2526-2533. https://doi.org/10.1001/jama. 2012.5669

10. Knaus WA, Draper EA, Wagner DP, Zimmerman JE (1985) APACHE II: a severity of disease classification system. Crit Care Med 13(10):818-829

11. Office for National Statistics; National Records of Scotland; Northern Ireland Statistics and Research Agency (2016) 2011 Census aggregate data. UK Data Service (Edition: June 2016). https://doi.org/10.5257/census/ aggregate-2011-1

12. NHS Digital (2019) The Health Survey for England (HSE) 2018

13. Scottish Intensive Care Society Audit Group (SICSAG) (2020) Scottish Intensive Care Society Audit Group report on COVID-19, As at 20 June 2020. Public Health Scotland

14. The National Intensive Care Evaluation (NICE) Foundation (2020) COVID19 in Dutch Intensive Care Units; Patient characteristics and outcomes compared with pneumonia patients in the ICU from 2017-2019. Accessed 27 Aug 2020

15. Spanish Society of Intensive and Critical Care Medicine and Coronary Units (SEMICYUC) (2020) G.T.E.I.S Boletín informativo 4 COVID-19. Accessed 28 June 2020

16. Grasselli G, Greco M, Zanella A, Albano G, Antonelli M, Bellani G, Bonanomi E, Cabrini L, Carlesso E, Castelli G, Cattaneo S, Cereda D, Colombo S, Coluccello A, Crescini G, Forastieri Molinari A, Foti G, Fumagalli R, lotti GA, Langer T, Latronico N, Lorini FL, Mojoli F, Natalini G, Pessina CM, Ranieri
VM, Rech R, Scudeller L, Rosano A, Storti E, Thompson BT, Tirani M, Villani PG, Pesenti A, Cecconi M, Network ftC-LI (2020) Risk Factors associated with mortality among patients with COVID-19 in intensive care units in Lombardy, Italy. JAMA Intern Med 5:10. https://doi.org/10.1001/jamai nternmed.2020.3539

17. Gupta S, Hayek SS, Wang W, Chan L, Mathews KS, Melamed ML, Brenner SK, Leonberg-Yoo A, Schenck EJ, Radbel J, Reiser J, Bansal A, Srivastava A, Zhou Y, Sutherland A, Green A, Shehata AM, Goyal N, Vijayan A, Velez JCQ, Shaefi S, Parikh CR, Arunthamakun J, Athavale AM, Friedman AN, Short SAP, Kibbelaar ZA, Abu Omar S, Admon AJ, Donnelly JP, Gershengorn HB, Hernán MA, Semler MW, Leaf DE, Investigators ftS-C (2020) Factors associated with death in critically ill patients with coronavirus disease 2019 in the US. JAMA Intern Med. https://doi.org/10.1001/jamainternmed.2020. 3596

18. UTIs Brasileiras (2020) Hospitals, Adult ICUs and Beds - Hospital Admissions in which Adult ICU Admissions were Required. Period: 01/03/2020 02/09/2020. https://www.utisbrasileiras.com.br/sari-covid-19/benchmarki ng-covid-19/. Accessed 9 Sept 2020

19. ANZICS CORE | Monash University SPRINT-SARI Australia (2020) Combined report on COVID-19 admissions to Australian and New Zealand ICUs. January 1 to March 31, 2020

20. Wang Y, Lu X, Li Y, Chen H, Chen T, Su N, Huang F, Zhou J, Zhang B, Yan F, Wang J (2020) Clinical course and outcomes of 344 intensive care patients with COVID-19. Am J Respir Crit Care Med 201(11):1430-1434. https://doi.org/10.1164/rccm.202003-0736LE

21. Linking of Global Intensive Care (LOGIC) (2020) Table Data COVID19. Characteristics and outcomes of COVID-19 and suspected COVID-19 patients in national registries. July 17, 2020. https://www.icubenchma rking.com/wp-content/uploads/2020/08/Tabledata-covid19-july20-1-1 pdf. Accessed 9 Sept 2020

22. Armstrong RA, Kane AD, Cook TM (2020) Outcomes from intensive care in patients with COVID-19: a systematic review and meta-analysis of observational studies. Anaesthesia. https://doi.org/10.1111/anae.15201

23. Prin $M$, Wunsch $H(2012)$ International comparisons of intensive care: informing outcomes and improving standards. Curr Opin Crit Care 18(6):700-706. https://doi.org/10.1097/MCC.0b013e32835914d5

24. Wunsch H, Angus DC, Harrison DA, Linde-Zwirble WT, Rowan KM (2011) Comparison of medical admissions to intensive care units in the United States and United Kingdom. Am J Respir Crit Care Med 183(12):16661673. https://doi.org/10.1164/rccm.201012-19610C

25. Bauer J, Brüggmann D, Klingelhöfer D, Maier W, Schwettmann L, Weiss DJ, Groneberg DA (2020) Access to intensive care in 14 European countries: a spatial analysis of intensive care need and capacity in the light of COVID19. Intensive Care Med. https://doi.org/10.1007/s00134-020-06229-6

26. Fowler RA, Webb SA, Rowan KM et al (2010) Early observational research and registries during the 2009-2010 influenza A pandemic. Crit Care Med 38:e120

27. Rowan KM, Harrison DA, Walsh TS et al (2010) The Swine Flu Triage (SwiFT) study: development and ongoing refinement of a triage tool to provide regular information to guide immediate policy and practice for the use of critical care services during the H1N1 swine influenza pandemic. Health Technol Assess 14:335-492. https://doi.org/10.3310/hta14 550-05

28. Grasselli G, Zangrillo A, Zanella A, Antonelli M, Cabrini L, Castelli A, Cereda D, Coluccello A, Foti G, Fumagalli R, lotti G, Latronico N, Lorini L, Merler S, Natalini G, Piatti A, Ranieri MV, Scandroglio AM, Storti E, Cecconi M, Pesenti A, Network ftC-LI (2020) Baseline Characteristics and outcomes of 1591 patients infected with SARS-CoV-2 admitted to ICUs of the Lombardy region, Italy. JAMA 323(16):1574-1581. https://doi.org/10.1001/ jama.2020.5394

29. Docherty AB, Harrison EM, Green CA, Hardwick HE, Pius R, Norman L, Holden KA, Read JM, Dondelinger F, Carson G, Merson L, Lee J, Plotkin D, Sigfrid L, Halpin S, Jackson C, Gamble C, Horby PW, Nguyen-Van-Tam JS, Ho A, Russell CD, Dunning J, Openshaw PJ, Baillie JK, Semple MG (2020) Features of 20133 UK patients in hospital with covid-19 using the ISARIC WHO clinical characterisation protocol: prospective observational cohort study. BMJ 369:m1985. https://doi.org/10.1136/bmj.m1985

30. Xie J, Wu W, Li S, Hu Y, Hu M, Li J, Yang Y, Huang T, Zheng K, Wang Y, Kang $H$, Huang $Y$, Jiang $L$, Zhang W, Zhong M, Sang L, Zheng X, Pan C, Zheng R, Li X, Tong Z, Qiu H, Du B (2020) Clinical characteristics and outcomes of critically ill patients with novel coronavirus infectious disease (COVID-19) 
in China: a retrospective multicenter study. Intensive Care Med. https:// doi.org/10.1007/s00134-020-06211-2

31. Alhazzani W, Møller MH, Arabi YM, Loeb M, Gong MN, Fan E, Oczkowski S, Levy MM, Derde L, Dzierba A, Du B, Aboodi M, Wunsch H, Cecconi M, Koh Y, Chertow DS, Maitland K, Alshamsi F, Belley-Cote E, Greco M, Laundy M, Morgan JS, Kesecioglu J, McGeer A, Mermel L, Mammen MJ, Alexander PE, Arrington A, Centofanti JE, Citerio G, Baw B, Memish ZA, Hammond N Hayden FG, Evans L, Rhodes A (2020) Surviving Sepsis Campaign: guidelines on the management of critically ill adults with Coronavirus Disease
2019 (COVID-19). Intensive Care Med 46(5):854-887. https://doi.org/10. 1007/s00134-020-06022-5

32. The WHO Rapid Evidence Appraisal for COVID-19 Therapies Working Group (2020) Association between administration of systemic corticosteroids and mortality among critically ill patients with COVID-19: a metaanalysis. JAMA. https://doi.org/10.1001/jama.2020.17023

33. Intensive Care National Audit and Research Centre (ICNARC) (2020) ICNARC report on COVID-19 in critical care. ICNARC, London 